\title{
How to Infer What Persistent Things Are Up to A Fregean Puzzle for Traditional Fregeans
}

\author{
Gersel, Johan
}

Document Version

Accepted author manuscript

Published in:

Inquiry

DOI:

10.1080/0020174X.2019.1610052

Publication date:

2023

License

Unspecified

Citation for published version (APA):

Gersel, J. (2023). How to Infer What Persistent Things Are Up to: A Fregean Puzzle for Traditional Fregeans. Inquiry, 66(1), 92-121. https://doi.org/10.1080/0020174X.2019.1610052

Link to publication in CBS Research Portal

\section{General rights}

Copyright and moral rights for the publications made accessible in the public portal are retained by the authors and/or other copyright owners and it is a condition of accessing publications that users recognise and abide by the legal requirements associated with these rights.

Take down policy

If you believe that this document breaches copyright please contact us (research.lib@cbs.dk) providing details, and we will remove access to the work immediately and investigate your claim. 


\title{
How to Infer What Persistent Things Are Up to: A Fregean Puzzle for Traditional Fregeans
}

\author{
Johan Gersel \\ Journal article (Accepted manuscript*)
}

\section{Please cite this article as:}

Gersel, J. (2019). How to Infer What Persistent Things Are Up to: A Fregean Puzzle for Traditional Fregeans. Inquiry. https://doi.org/10.1080/0020174X.2019.1610052

This is an Accepted Manuscript of an article published by Taylor \& Francis in Inquiry on 26 Apr २०19, available online:

DOI: http://www.tandfonline.com/10.1080/0020174X.2019.1610052

* This version of the article has been accepted for publication and undergone full peer review but has not been through the copyediting, typesetting, pagination and proofreading process, which may lead to differences between this version and the publisher's final version AKA Version of Record.

Uploaded to CBS Research Portal: August २०२० 


\section{How to infer what persistent Things are up to}

- A Fregean Puzzle for traditional Fregeans

\section{Forthcoming in Inquiry}

\section{By Johan Gersel}

How do we inferentially unify separately acquired empirical information into a single comprehensive picture of the lives of persistent particulars? This paper argues that hidden in such inferences is a Fregean puzzle that can only be solved by individuating our demonstratives thoughts in terms of object-dependent Fregean Senses. I begin by characterizing some constraints on a non-skeptical account of our inferential unification of empirical information. I then go on to show that traditional Fregean views of Sense cannot explain the rationality of such inferences; the consequence of which would be widespread skepticism concerning fundamental aspects of our empirical worldview. I show how the theory of object-dependent Senses can account for the rationality of the puzzling inferences.

Lastly, I consider the alternative that we abandon a Fregean explanation of the rationality of inferences. While not fully dismissing that option, I briefly raise, what I take to be, a daunting challenge that uniquely faces non-Fregean views of rational inference.

Our common-sense empirical worldview includes the idea that we gradually increase our knowledge about the continuing lives of persisting physical particulars. To support this, a non-skeptical view of our knowledge gathering capacities must allow for the ability to rationally unify the temporally dispersed information we get about single entities. Part of the process of unifying information is by performing inferences where one moves from thoughts on the form 'that object is F' and 'that object is G' and concludes that a single object is both F and G. While I take it to be uncontroversial that we perform such inferences, a pressing question is what logical form we should ascribe to them and how we can account for their rationality. I want to suggest that hidden in such inferences is a Fregean puzzle that is best solved by adopting the view that some thought content is individuated in terms of objectdependent Fregean Senses. Specifically, I will argue that the content of at least certain of our singular demonstrative perceptual judgements must be individuated in terms of object-dependent Senses. Of 
course, this leaves ample room for other types of thoughts to have different forms of Sense. However, those defending the object-dependency of Sense have primarily argued for this in relation to singular demonstrative thoughts, and those objecting to the view have mostly done so on principled grounds attempting to argue that Senses need never be object-dependent. I will present a Fregean puzzle facing such objectors.

\section{The Nature of the puzzling, information-unifying Inferences}

To begin, we need to elaborate on the puzzling type of inferences. We clearly expand our empirical worldview by performing inferences of all kinds. I will argue that a non-skeptical account of our empirical worldview requires that at least some of our inferences exhibit four distinctive features:

1. They unify separately acquired pieces of information

2. They initially entertain this information in premises that are immune to errors of misidentification

3. They trivially trade on the identity of the objects referred to in the initial premises

4. They are rational

This first section of the paper is devoted to defending that claim.

Our concern is with inferences that unify pieces of information acquired over time, such as the one employed in the following example: Todd, who is at the zoo, absentmindedly gazes at a playing lion cub. First, he sees it graciously jumping onto a log, and he forms the judgement 'that lion jumped graciously'. He has continued uninterrupted awareness of the lion cub for an extended period, and later sees it clumsily falling to the ground ${ }^{1}$. He then forms the judgement 'that lion fell clumsily'. A while later, based on those two judgements, Todd infers the conclusion 'that lion was both jumping graciously and falling clumsily' and is surprised at how a single creature could exhibit both such grace and such clumsiness. Todd's surprise, which occurs later than his two experiences, shows that prior to the mental process of inference he had no personal-level representation, and hence no personal-level knowledge, that it was one and the same lion cub that both jumped and fell. Rather, it is the very

\footnotetext{
${ }^{1}$ The precise length of the period of awareness is irrelevant for the argument. It just needs to be sufficiently short to allow uninterrupted attention, and sufficiently long to allow for the metaphysical possibility that an elaborately staged undetected switch of lion cubs could be accomplished within such a time period.
} 
Prepublication version - please cite the published version.

mental process of inference which has led to the novel knowledgeable thought that a single lion cub both jumped graciously and fell clumsily.

Intuitively, the pieces of information such inferences unify are separately acquired. One could argue that it is a single acquisition of empirical information that allows one to appreciate that a seen patch of paint is both red and square. However, in the case above, we seem to be dealing with two occurrences of information acquisition: one informing Todd about the jumping, and a subsequent information acquisition informing him about the falling. The rough idea is that all our information is not immediately unified upon our acquisition of $\mathrm{it}^{2}$. We do not see the lion as both currently falling and having jumped a minute ago. We first see the lion simply as jumping. Later, we see it simply as falling. If we fail to unify this information it is due to a lack of inference, not due to any lack of attention to what is given immediately in a single perception ${ }^{3}$. I am working based on the widely accepted assumption that perceptual information gathering initially motivates singular thoughts which figure as starting premises in subsequent reasoning: paradigmatically singular demonstrative thoughts with the logical form 'that $\alpha$ is $\mathrm{F}^{4}$. Hence, I am concerned with the inferential unification of separately acquired pieces of information that are present in two such co-referential singular thoughts.

The inferences I am concerned with possess the second feature that both initial thoughts exhibit what in the philosophical literature has been called immunity to error through misidentification ${ }^{5}$. Hence, I am relying on the assumption that at least some empirical singular judgements possess such immunity. Empirical evidence might mislead under unfortunate circumstances. It may be the case that nothing is red even though an experience has motivated me to judge that something is. However, it has been argued that some judgements are immune to another form of error; that of misidentifying what object one's evidence concerns. A judgement, say, 'that $\alpha$ is F', exhibits immunity if the relation between the judgement and the evidence it is based upon, is such that the subject cannot rationally doubt that it is $\alpha$ that is F while simultaneously taking that evidence to support the judgement that something is F. The

\footnotetext{
${ }^{2}$ I am here talking about unification at the conscious level of the subject. Recanati (2012:98) would argue that there is a further question of whether the information is subconsciously unified in a single mental file. I will later engage with views like his in more detail.

${ }^{3}$ It may be that occurrences with very minute temporal distances are inherently perceived as unified in a temporal order. However, we clearly unify perceptual information that is acquired at more distant times.

${ }^{4}$ For defense of this see for example Evans (1982), Campbell (2002), Martin (2002) Burge (2009)

5 The idea is originally from Shoemaker (1968) and extensively developed in Evans (1982). At times, I will simply use 'immunity' to refer to immunity to error through misidentification.
} 
Prepublication version - please cite the published version.

relation between the reference-fixing of ' $\alpha$ ' and one's information about the presence of F'ness, is such that if anything is shown to be $\mathrm{F}$ by that evidence, then it is $\alpha$ that is $\mathrm{F}$.

By now, it is widely acknowledged that certain of our singular thoughts, especially demonstrative judgements, can exhibit immunity to error through misidentification regarding the attribution of empirical properties ${ }^{6}$. However, it is still worthwhile to point out for potential sceptics why it is difficult to relinquish this idea. If all singular judgements lacked immunity, then one could always rationally remain steadfast in one's judgement that something is F, while being skeptical as to whether it is $\alpha$ that is F. However, if one allows the rationality of this skeptical challenge for every empirical singular judgement, then it is difficult to see how the challenge could ever be met; the consequence would be rampant skepticism. To determine whether it was indeed $\alpha$ that was F, I would need to know something more about $\alpha$, say, that it was uniquely G. Combine this with the knowledge that whatever I found out was F was also G, and I would be able to conclude that $\alpha$ was indeed F. However, per hypotheses, even though I know that something is G, I can still wonder whether it is indeed $\alpha$ that is G, and so the regress gets going. The suggested solution is that this regress stops once we reach judgements that possess immunity ${ }^{7}$. The typical explanation of how judgements can possess such immunity is that it is a feature of certain singular concepts, especially demonstrative concepts, that they inherently refer to the object from which a certain piece of information derives ${ }^{8}$. The literature on how to understand information-based reference fixing is enormous and various competing accounts are flourishing 9 . My argument will not depend on the details of the story given, but merely on the assumption that we do indeed make inferences where we unify information from several immune empirical demonstrative judgements. As suggested above, this premise must be accepted if we are to avoid widespread skepticism about the unification of our empirical knowledge into a comprehensive, temporally extended picture of the continuing lives of single objects.

\footnotetext{
${ }^{6}$ Evans (1982), Burge (2005) Campbell (2002), Recanati (2012), Dickie (2015)

${ }^{7}$ I am working on the assumption shared by among others Heck (2012), Fine (2007), Broome (2013) and Pryor (2001), that the rationality of accepting a conclusion is in some way a matter of inheriting the justification one had for believing the premises of the inference. My approach thus relies on the normative correctness of foundationalism in Harman's (1986, 28) unique understanding of the term; a position he rejects. It is beyond the scope of the present paper to argue fully against Harman's view and respond to his objections.

${ }^{8}$ Evans (1982), Burge (2005) Campbell (2002), Recanati (2012)

${ }^{9}$ See the essays in Jeshion (2010) for a variety of views
} 
Prepublication version - please cite the published version.

It is important for the argument to come that judgements possessing immunity must somehow stand out for the rational thinker. The notion of immunity is defined in terms of what a rational subject can and cannot doubt. However, if rational subjects are insensitive to which judgements possess immunity, then the possession of immunity cannot explain why a certain form of doubt is impossible for these rational thinkers. If we maintain that a rational subject has no sensitivity to the presence of the features that make a certain form of doubt unfounded, then it would be utterly mysterious why such a rational subject was unfree to entertain those doubts in relation to just some of his judgements. Hence, in one way or another, rational subjects must be sensitive to the fact that their empirical demonstrative judgements have their reference intimately connected to the ancestry of specific pieces of information. Of course, subjects need not be able to make this idea explicit, nor need they even possess the concepts of 'information' or 'reference'. But at the least, their judging practices must display an ability to identify, in some weak sense, both those demonstrative judgements that exhibit immunity and the information they exhibit immunity in relation to ${ }^{10}$. Moreover, they must appreciate these features as ensuring a tie between the evidence received and the reference of the judgement. They need not be able to make explicit, nor even entertain, the theory that explains the connection between the reference of $\alpha$ and their evidence. But at the very least, they must take it as primitive that this tie holds and, hence, find any skeptical challenge to their assignment of $\alpha$ as the potentially F object more puzzling than pressing.

The next issue is to determine what logical structure we should ascribe to the inferences in question. The claim made so far is that our empirical worldview requires that we make inferences that move from the following premises:

P1: That $\alpha$ is F (that lion was jumping)

P2: That $\alpha$ is $\mathrm{G}$ (that lion was falling)

To the conclusion that:

$\mathrm{C}$ : That $\alpha$ is $\mathrm{F}$ and $\mathrm{G}$ (that lion has been jumping and falling)

${ }^{10}$ Evans $(1982,180)$ talks of one's thinking about an object being controlled by certain way of getting information. 
Prepublication version - please cite the published version.

Yet, at this stage, all that is presupposed is that the two demonstrative judgements co-refer. We have yet to determine whether the singular concepts employed allow one to immediately rationally conclude from the two premises that it is one and the same thing that is $\mathrm{F}$ and $\mathrm{G}$, or whether more supporting premises are required. As much discussion of 'Hesperus' and 'Phosphorus' has made abundantly clear, there can be co-referential singular judgements where it is irrational to unify the information they contain. The following alternative form of inference suggests itself:

$\mathrm{P} 1 *$ : That $\alpha$ is $\mathrm{F}$ (that lion was jumping)

$\mathrm{P} 2 *$ : That $\beta$ is $\mathrm{F}$ (that lion was falling)

P3*: that $\alpha$ is identical to that $\beta$ (that lion is identical to that lion)

$\mathrm{C}$ : That $\alpha$ is $\mathrm{F}$ and $\mathrm{G}$ (that lion has been jumping and falling)

Let us call an inference that eschews an identity premise a 'Hesperus-Hesperus inference' and an inference that employs such a premise a 'Hesperus-Phosphorus inference'11. Obviously, we sometimes employ identity premises as part of the reasoning we use in unifying separately acquired pieces of empirical information. However, I am suggesting that this cannot universally be the case ${ }^{12}$. All my Fregean puzzle requires is that we sometimes rationally unify separately acquired pieces of information from immune judgements by means of Hesperus-Hesperus inferences. It is important to notice that this claim does not rely on any phenomenological considerations about how our inferential practices strike us, nor one any linguistic considerations about how we present our inferences in argument. I acknowledge that a mental inference might appear to lack an identity premise, both to the reasoner and in its linguistic representation, even though it psychologically relies on a suppressed identity premise. The possibility and widespread occurrence of enthymemic reasoning is fully compatible with my arguments. It is rather for epistemic reasons that we must accept that some of these inferences have the Hesperus-Hesperus form ${ }^{13}$.

\footnotetext{
${ }^{11}$ Notice my terminology does not presuppose that one is rational in employing either type of inference. Hence, an irrational subject can form a Hesperus-Hesperus inference even if his premises do not employ concepts that rationally allow this.

${ }^{12}$ This claim is controversial. Millikan $(2000,172)$ outright denies that we can ever unify our information about particulars through inferences of the Hesperus-Hesperus kind; however, I take hers to be the minority view.

${ }^{13}$ Another option is to claim that we are justified in such reasoning by employing a form of immediate inference that lacks any inherent connection to truth-entailment. If this is the case, then no sensitivity to a relation between the truths of the premises and the truth of the conclusion forms part of the subject's rational grounds for inference, at best such a connection
} 
Prepublication version - please cite the published version.

To see this, we need to distinguish between the epistemic burden that is acquired by employing a premise as opposed to following a valid inference rule. Clearly the Hesperus-Hesperus inference will only lead to knowledge if the two singular thoughts co-refer. So, once we have acknowledged that premises can be suppressed in enthymemic reasoning, why is it of importance that the inference has the Hesperus-Hesperus, rather than Hesperus-Phosphorus, form? After all, the identity premise in question must be true if either form of inference is to lead to knowledge. The crucial difference is that one incurs a further epistemic burden by employing a premise in one's reasoning as opposed to that incurred by inferring according to a valid inference pattern.

To rationally employ a premise in one's empirical reasoning, one must have evidence that supports one in taking the premise to be true. A conclusion cannot amount to empirical knowledge unless the premises it is derived from are based on adequate evidence ${ }^{14}$. However, rationally following an inferential pattern comes with no equivalent requirement ${ }^{15}$. To acquire knowledge based on inference, all that is required is that one's inferential pattern is in fact proper and that one performs the inference due to sensitivity to its inferential form. One need not possess positive evidence in favor of the propriety of one's inferential pattern ${ }^{16}$. Thus, an increased justificatory burden is placed upon reasoning subjects once we characterize their inferences as employing further suppressed premises. While the relevant identity claim must be true if an inference on the Hesperus-Hesperus form is to provide knowledge, the subject need not have evidence supporting this identity claim. It is, given the nature of the conceptual capacities exploited by the subject in forming the two singular thoughts, trivial to the subject that they co-refer. In contrast, an inference on the Hesperus-Phosphorus form can only enable knowledge if the subject has substantial evidence in favor of the identity premise.

will be a fact external to the features that motivate the subject to infer. Harman $(1986,123)$ considers such a view; but remains undecided about its feasibility. In section three I will raise a challenge for this approach.

${ }^{14}$ Maybe we have inherent warrant for believing certain propositions as suggested by Wright (2004). However, these certainly won't be as specific as our identity premise in question concerning a specific object, nor specific enough to support it by themselves.

15 On pain of infinite regress, we cannot require that the adequacy of every inference rule we employ figures as a premise in the argument. See Caroll (1895)

${ }^{16}$ How to fully account in general for the nature of inference and our justification for following inferential patterns is a thorny issue that falls beyond the scope of this paper (see Boghossian 2014). All I aim to explore in this paper is the consequences that follows from adopting the Fregean idea that sensitivity to the validity of an inference is a necessary requirement for rational inference. What seems clear, however, is that rationally following an inference pattern comes with different justificatory requirements than rationally employing a thought as a premise. 
Prepublication version - please cite the published version.

In our case, this epistemic difference spells trouble for the idea that all such inferences take the Hesperus-Phosphorus form. The form of empirical reasoning we are concerned with is among the most basic forms of information unification. It is very difficult to see how we could possibly possess evidence sufficient to support a specific empirical identity claim without already having unified empirical information gathered over substantial periods of time. To support an identity claim, one must possess substantial information about both the specific objects involved and most likely general information about their sort as well. This might involve knowledge about an object's movement capabilities, its speed, trajectory, and location, as well as knowledge about its sort's potential for persistence across change in properties, typical distribution, and so on. However, knowledge of these types of properties seems to require that one has already unified empirical information gathered over time.

How, for example, could I possibly know what changes destroy a naturally occurring entity, rather than merely alter it, unless I have already unified information about it gathered over time; such as information about how it looks from various angles, in various lighting conditions, and when it undergoes change. Likewise, determining the typical movement patterns of an object requires that one unify temporally dispersed information. Nor is it possible to support general premises, such as the assumption that two perceived objects are likely identical when they are qualitatively similar and seen in close temporal and spatial proximity, unless we already have an idea of how single objects behave over time. Hence, we cannot in turn rely on knowledge of that general principle as the premise that enables us to acquire unified knowledge of the temporal lives of objects in the first place.

The ability to unify empirical information into a progressing picture of the lives of single objects is an extremely basic feature of our ability to acquire knowledge of the nature of the objects around us. Therefore, it is difficult to see how we could possibly possess sufficient evidence to support identity premises without already having performed such unification. At the very least, the burden of proof must rest on anyone who argues that this is possible. Hence, until it has been shown how we can collect sufficient evidence to support identity claims, without at any stage relying on the previous inferential unification of information separately acquired, it must be acknowledged that at least some very basic information unification takes the form of inferences that do not involve identity premises. Instead, these inferences trivially trade on the identity of the referents of the two demonstrative thoughts in which the 
Prepublication version - please cite the published version.

information to be unified is represented. Thus, some inferences that unify separately acquired pieces of empirical information between two immune judgements must have the Hesperus-Hesperus logical form $^{17}$.

The final feature is that the inferences we are concerned with are at times rationally performed. The irrationality of an inference defeats knowledge of the conclusion. Hence, if we accept that we have knowledge which amounts to a single picture of the temporally unfolding lives of particulars, then we cannot be irrational in making the inferences that this knowledge relies upon. How to account for our conceptual capacities so that they can ground the rationality of these Hesperus-Hesperus inferences is what will occupy the rest of the paper.

\section{The rationality of an Inference}

According to Frege, an inference is a sui generis mental process. It is a form of judgement where one moves from a series of thoughts acknowledged as true, to the acknowledgement of a further thought as true ${ }^{18}$. An inferential conclusion is rational when it has followed the laws of proper thinking. 'Rationality', as I will use the term, is a normative accolade expressing the propriety of making a certain judgment or holding a certain belief. In our case of inferential judgements, such propriety can be split in two: First, the concluding judgement must be properly inferred from a series of premises, beliefs or judgements, that one consciously or unconsciously entertains; second, these premises must themselves be properly entertained. There is little hope that we can give a reductive account of the laws governing inferential thinking ${ }^{19}$. For example, it is possible to believe a set of premises from which a judgement deductively follows and make that judgement based on entertaining those premises without one's judgement being properly based on those premises. For example, one might have formed one's conclusion simply because the premises reminded one of that thought, not because they entailed its truth. I will simply take the notion of proper inferential basing to be primitive. However, we can still

\footnotetext{
17 This issue of how we can justify identity claims surely demands greater attention than what it has been given here. However, I take the idea that we need basic Hesperus-Hesperus inferences in our information gathering to be a sufficiently intuitive and appealing idea to make it of interest to establish that this view is only available for Fregeans if they acknowledge object-dependent Senses.

18 Textor $(2011,77-79)$

${ }^{19}$ Ibid
} 
Prepublication version - please cite the published version.

elucidate the nature of inferential rationality by presenting various insufficient but necessary requirements on rational inference ${ }^{20}$.

Minimally, the aim of judgement is in some sense truth ${ }^{21}$. Hence, the laws of proper thinking must in some way relate to the conditions under which there are grounds for taking one's conclusion to be true. We can begin the characterization of rationality by separating these truth-related laws of thought from various non-truth related laws of thinking, such as the pragmatic law that one should think positive, or the prudish law that one ought not have dirty thoughts. Our concern is with how we should characterize the truth-related laws of inference and, consequently, with how we should understand those conceptual capacities that enable rational thinkers to possess sensitivity to these.

On a traditional view, most explicitly defended by Frege ${ }^{22}$, the truth-related laws of thought that govern inference consists of the logical laws of deductive inference. On this view, a type of inference is rational only if it is logically valid and performed due to some form of sensitivity to its validity; although the full rationality of accepting the conclusion also requires that one was rational in holding the initial premises true. While it is controversial how to segregate views into Fregean and nonFregean, I will take a Fregean view to be any view according to which rational inference requires that the subject infers based on sensitivity to the logical validity of the inference ${ }^{23}$. As logical validity depends on reference, this means that the features to which a rational thinker is sensitive must suffice to determine sameness and difference of reference. On a minimal reading, this is all Frege meant by 'Sense'; a feature, to which rational thinkers are sensitive, which individuates thoughts with finer grain that differences in reference, but which suffices to determine reference ${ }^{24}$.

\footnotetext{
${ }^{20}$ The idea that sensitivity to validity (or immediate implication) is merely a necessary but insufficient requirement for rational inference takes care of most of Harman's (1986) objections. However, the problem of the rationality of inductive inference is still untouched. Yet, this shouldn't affect the current argument, since we have already questioned that general principles as can function as the basic premises of these specific cases of basic information unification. This is a key disagreement between mine and Harman's $(1986,44)$ view of such rational information unification.

${ }^{21}$ Some take the aim to be stronger as in justified truth or knowledge (See for example Smithies (2012) and Littlejohn (2013)), but the present argument can suffice with the weaker claim.

${ }^{22}$ See Frege (1906?) §15 of his "17 key sentences in logic" and Textor (2011: 78)

${ }^{23}$ See for example Heck (2012), Sainsbury (2012), Fine (2007), and Evans (1982) for a series of different definitions of the terms 'Fregean' and 'Millian'.

${ }^{24}$ See Frege (1982). Notably this account doesn't require that differences in Sense are solely explained by differences in semantic or representational features. In this usage, I follow Burge (1977), Evans (1982), McDowell (1984), Campbell (1987), Forbes (1987) and Heck (2012); contrary to that of Sainsbury (2012) and Fine (2007). Neither does this view require that Fregean accounts necessarily take Senses to be descriptive modes of presentation, as has otherwise been widely
} 
Prepublication version - please cite the published version.

The Fregean position allows for various characterizations of the conceptual capacities that enable rational subjects to exhibit sensitivity to the validity of their inferences. The currently popular view is a syntactic account, or the Fregean Guise view, where it is our sensitivity to the sameness of syntactic vehicle types that accounts for our sensitivity to validity ${ }^{25}$. Then there are two semantic views, the descriptivist $^{26}$ and the object-dependent Senses view ${ }^{27}$, where it is sensitivity to the sameness of the reference of our concepts that enables our sensitivity to the validity of our inferences. How to account for the fine-grained individuation of thoughts and our conceptual capacities to appreciate such individuation is what separates the various Fregean views.

Non-Fregean approaches to rationality will argue, in one way or another, that the rationality of an inference doesn't depend on sensitivity to its logical validity. Hence, they are free to claim that when we rationally infer we are sensitive to features that fall short of settling reference. Commonly, they will argue that we are sensitive to validity-conducive features or features that are reliable signs of validity under ordinary conditions ${ }^{28}$. In the final section of the paper, I will consider such non-Fregean views. Though I will speak despairingly of them, it is beyond the scope of the paper to present a conclusive argument against them. The main conclusion of the paper will be that if one wants to avoid the separation of rational inference from sensitivity to validity, then one must acknowledge that at least some of our singular concepts are individuated in terms of object-dependent Senses.

\section{The Fregean puzzle and rationality as sensitivity to validity}

In the current section I want to argue that, among the Fregean approaches, it is only the ObjectDependent Senses view that can adequately account for our capacity to make rational inferences of the

\footnotetext{
suggested; see for example Perry (1977), Bach (2010), and Sainsbury (2012). Hence, while Sainsbury (2012), Fine (2007) and Salmon (1986) take their views to be non-Fregean, because they assume that differences in Sense must be grounded in representational differences, their views are Fregean in my terminology. See Recanati (2012: 243-246) for a recent discussion. While Heck (2014) claims that his own view is non-Fregean this is largely due to an arbitrary choice as to how he uses the notion 'content'. Heck $(2012,52)$ agrees his view is a functional variant of Fine's who acknowledges that content determines inferential role. Hence, Heck's view is also Fregean according to my terminology.

${ }^{25}$ This view is held by Sainsbury (2012), Burge (1977), Fine (2007), Fodor (1994), Salmon (1986), Heck (2012), Pryor (2016), Recanati (2012), and Bach (2010). While Fine claims that his relations of coordination create a difference in content, see Heck (2014) for an argument that only formal syntactic features explain inferential relations on both Heck's own and Fine account.

${ }^{26}$ This view is advocated by Dummett (1973), Searle (1982), and Chalmers (2002). It's attributed to Frege, but rejected as untenable in Perry (1977)

${ }^{27}$ This view is held by Evans (1982), McDowell (1984), Campbell (2002), Brewer (2011).

${ }^{28}$ See for example Brown (2004) and Millikan (1993).
} 
Prepublication version - please cite the published version.

type characterized in the first section of the paper. The puzzle at hand concerns ordinary cases of employing inference in unifying information one has stored regarding a singular object. As argued, such inferences are central to how we unify our separate pieces of information about particulars into a single comprehensive view of them. The puzzle to come stems from two features of such inferences that seem to force our account of how Sense determines reference in opposite directions.

First off, the two premises involved in the inference are presumed to be immune to errors of misidentification with respect to the consciously separate information that supports the predication involved. Moreover, it is inherent to immunity that the rational subject must be sensitive to the fact that his thoughts inherently refer to the object from which he has the information he bases his judgement upon. This means that Todd must be sensitive to the fact that his first premise 'that lion was jumping' has its reference inherently tied to the object from which his jumping information derives. Likewise, he must be sensitive to the fact that his second premise refers to the object from which his falling information derives. Hence, it seems that the cognitive role that the first demonstrative plays in Todd's rational thinking, its Sense, suggests that the reference of that demonstrative is tied specifically to his jumping information, and likewise with the latter demonstrative and his falling information.

However, if the inference Todd employs in unifying his information is a Hesperus-Hesperus inference, then Todd infers as if he can appreciate the co-reference of his singular thoughts merely through his exercise of the conceptual capacities involved in entertaining those thoughts. The defining feature of a Hesperus-Hesperus inference is precisely that its rationality relies on the ability to trivially appreciate the co-reference of the concepts involved due to the nature of one's conceptual capacities. That Todd uses this type of inference suggest that the Sense of the involved terms ensure that they have their references determined in the same way.

The core of the puzzle is that Todd's concept 'that lion' plays a complex cognitive role in his rational thinking. It plays the role of having its referent essentially tied to two separate pieces of information when used respectively in the first and second demonstrative judgement. It also plays the role of having its reference determined in the same way in both uses when employed in the Hesperus-Hesperus inference. Finally, its cognitive role is such that it is informative for Todd to employ his concept 'that lion' in the inference in question, so as to learn that one and the same lion both jumped and fell. If Todd is ever fully rational in the type of information unification we have considered, this means that he 
Prepublication version - please cite the published version.

has correctly identified the cognitive roles for each of his concepts and, thus, he is correct both in taking them to trivially co-refer and in taking the concepts to be individually immune with respect to the separate pieces of information. Any Fregean theory owes an account of what Senses are, such that Todd's grasp of the Sense of his concept 'that lion' can explain how the concept can have that complex cognitive role in his rational cognition.

We can see from the setup above that the puzzle doesn't take the form of a typical skeptical challenge, where we question how Todd can possibly know that he isn't in a misleading setup where, say, two identical lion cubs are dexterously switching places. It is acknowledged that this isn't the case, and it is furthermore acknowledged that Todd need not have any positive evidence that rules out that he is in such a knowledge defeating scenario ${ }^{29}$. Hence, the puzzle presumes that Todd has correctly identified the complex cognitive role of the concepts involved in his inference. Instead, the Fregean puzzle raises the question of what a Sense could possible be, if Senses are to be something that, first, Todd can grasp and, second, something that can explain the complex cognitive role that the concept 'that lion' plays in Todd's rational thought. We need to be given an account of what Senses are, such that a single graspable Sense can both ensure the validity of a knowledge granting Hesperus-Hesperus inference and ensure that the two judgements it involves possess immunity with regard to separate information.

Notice, that it is important that an adequate account of Sense must ensure both co-reference and immunity. If sameness of Sense failed to ensure co-reference, then grasp of sense couldn't amount to sensitivity to validity, as sameness of sense would be compatible with difference of reference. If Sense failed to ensure immunity, then grasp of the Sense of an immune concept wouldn't bar the subject from doubting whether $\alpha$ was indeed the object that was F. The Fregean can acknowledge that when defeating conditions occur, we fail to properly grasp the cognitive role of our concepts. But what the Fregean needs to supply, is a positive account of what Sense are, such that, when properly grasped, the nature of these Senses explains Todd's sensitivity to the validity and immunity of his knowledge granting inference.

I will now go through the three Fregean positions and present their accounts what Senses are and what capacities we employ in grasping sameness of Sense. As we will see, both the descriptive Fregean and

${ }^{29}$ I owe thanks to an anonymous referee for the clarifications of how the essence of the puzzle differs from skeptical worries about defeating conditions. 
Prepublication version - please cite the published version.

the Fregean Guise view falls short of providing an adequate explanation of the rationality of Todd's inference. Despite their differences, these two views possess an important structural similarity in their account of Sense, and I will in unison refer to them as traditional Fregean Views. The traditional views take Frege's discussion of informative identity statements to have established that our grasp of the rational inferential role of concepts cannot consists in a form of direct knowledge of the sameness of the referents of our thoughts. Instead, traditional Fregeans argue that it is by being sensitive to the sameness of intermediaries that in turn determine reference that we have a mediated sensitivity to the validity of our inferences. Thus, on these views, Senses are some form of intermediaries, sensitivity to which accounts for our sensitivity to validity, despite our lack of any immediate epistemic relation to the referent of our thinking which would allow us to settle co-reference between thoughts ${ }^{30}$. Thus, while Senses determine referents, they function as intermediaries between these referents themselves and our rational engagement in conceptual thought. The traditional Fregeans thus give the following account: Grasp of Sense is grasp of a mental intermediary. The next step is to explain how the nature of this intermediary is such that it determines reference. The challenge for the traditional Fregean is thus to explain how this intermediary can possibly play the complex cognitive role of both ensuring the validity of the knowledge granting Hesperus-Hesperus inference and the separate immunity of the individual premises.

In contrast to the traditional Fregeans stands the Object-Dependent Senses view. On such accounts, our capacity for rational inference is explained in terms of a subjectively accessible epistemic relation to the very referent of our thoughts ${ }^{31}$. Our grasp of Sense is thus explained in terms of some form of rationally significant sensitivity to the very referent of the premises. The varying Senses that coreferential thoughts can possess are then individuated in terms of a multiplicity of such epistemic relations. Each of these relations allow one to appreciate the co-reference of a set of thoughts that are issued based on that relation, but such epistemic relations will not allow one to trivially appreciate the co-reference of thoughts that are based on different epistemic relations to that same referent. As we will see, it is the view of Senses as an intermediary between the subject and his referents that will stand in

\footnotetext{
${ }^{30}$ See Dummett (1973: 91) and Braun $(2001,256)$ for clear expressions of this view.

${ }^{31}$ My argument works at a level off abstraction where we can remain neutral as to how we understand this epistemic relation, as long as it suffices, according to one's epistemic theory, to provide knowledge of sameness of referent. It is most commonly characterized as a non-representational relation of acquaintance (see Campbell 2002, Brewer 2011, Travis 2007), but many competing theories exist (see Evans 1982, McDowell 1996).
} 
Prepublication version - please cite the published version.

the way of an adequate account of the rationality of the inferences we are concerned with; and that is why the Object-Dependent Sense view can alone provide a Fregean solution to our puzzle.

\section{The Descriptivist Fregean}

It is quite straightforward for the descriptive Fregean to explain how we can be sensitive to the validity of an immediate Hesperus-Hesperus inference even though we lack direct sensitivity to the identity of the referent of our concepts. Their solution is to claim that the Sense of a concepts is a set of satisfaction conditions that determine its reference. It is by being sensitive to the fact that two separate uses of singular concepts each require their referent to uniquely satisfy the same conditions that we are sensitive to validity. If the same conditions must be satisfied by the referent of two concept tokens, then trivially these two concept tokens must share their referent if any of them refer; which will in turn ensure the validity of the immediate Hesperus-Hesperus inference. The challenge for the descriptivist Fregean is to present a set of satisfaction conditions that can render Todd's inference valid and, at the same time, allow the performance of the inference to figure essentially in Todd's acquisition of the novel knowledge that a single lion cub both jumped and fell.

If immunity is to be conserved, then it must be part of the satisfaction conditions placed on the referent of an information-based singular concept that it refers to the object from which the information in question derives. The descriptivist will argue that it is precisely by appreciating this part of the satisfaction conditions of his singular concept that Todd grasps the immunity of his judgement. This means that it must be part of the satisfaction conditions of Todd's first use of the concept schema 'that lion' that it refers to the object from which his jumping-information derives. Likewise, it must be part of the satisfaction conditions of Todd's second use of the concept schema 'that lion' that it refers to the object from which his falling-information derives.

Yet, this leaves the descriptivist in a bind. If, on the one hand, the satisfaction conditions of Todd's two uses of the concept schema differ then he is, by the descriptivist's own reasoning, using demonstrative concepts with different Senses on the two occasions. In which case, his inference cannot rationally take the immediate Hesperus-Hesperus form. If, on the other hand, we take it to be part of the satisfaction conditions of both uses of Todd's concept schema that the concept refers to the object from which both his falling and his jumping information derives, then the inference plays no significant epistemic role in providing him with novel knowledge. It has become a trivial fact that Todd's concept 'that lion' must 
refer to something which both jumped and fell; for this is part of the very satisfaction conditions it places on its referent. And these are satisfaction conditions Todd is aware of when using the concepts, as it is such awareness which explains his capacity for rational concept use. At best, performing the inference could provide Todd with evidence that his singular concept does in fact refer; however, that is not the knowledge that Todd lacks prior to the inference. Prior to his inference, Todd has no doubt that both his premises refer and that they refer to the same entity. His problem is simply that he hasn't consciously connected the information in his two premises. However, if the descriptivist Fregean is right, this is impossible. Either Todd cannot rationally treat his two premises as trivially co-referring, alternatively, he must treat it as trivial that they refer to something which both jumped and fell. The only other option is to reject the immunity of either premise.

\section{The Fregean Guise theory}

The Fregean Guise theory faces the immediate challenge of explaining how we can appreciate the validity of our inferences when we are neither directly sensitive to the sameness of the referents of our thoughts, nor to the sameness of the features that fix their referents ${ }^{32}$. Their solution is to argue that we are sensitive to the syntactic sameness of reference bearing guises, or representational vehicles ${ }^{33}$. They claim that our capacity for rational inference consist in the ability to correctly identify when separate representational vehicles are of the same syntactic type. Moreover, they claim that syntactic types are individuated partly in terms of their referent. This means that if we are sensitive to two representational vehicles as being of the same syntactic type, then such sameness of type ensures sameness of reference $^{34}$. Thus, if we treat two thoughts as eligible for Hesperus-Hesperus inferences due to our sensitivity to the sameness of their syntactic type, then the inference will be performed due to sensitivity to its validity and, therefore, it will be rational.

\footnotetext{
${ }^{32}$ See Burge (1979) and Kripke (1980) for the initial arguments as to why we need not grasp the reference determining features of our concepts

${ }^{33}$ There are multiple ways of fleshing out the idea of syntax. Pryor $(2016,319)$ argues that we should take ourselves to be sensitive to the syntax of graph-like structures, rather than representational vehicle tokens which is the view of Fodor (1990). These subtleties are irrelevant for the present discussion. They central issue is whether rationality consist in sensitivity to mere syntactical features that suffice to determine semantic features, or whether it also consists of sensitivity directly to the semantic features themselves.

${ }^{34}$ It is also an option to claim that rational inference consists in syntactic sensitivity to guises while denying that these are individuated in terms of shared reference. This will yield a non-Fregean view of rational inference where rationality doesn't consist in sensitivity to validity. Such views will be discussed in section 3 .
} 
Prepublication version - please cite the published version.

The next task for the Fregean Guise theory is to explain what capacity it is that enables us to grasp when two concepts share their guises, all the while these guises are partly individuated in terms of their reference. Importantly, the Fregean Guise theorists cannot explain our sensitivity to sameness of guise partly in terms of our direct sensitivity to the sameness of the referent of the syntactic vehicles. For they introduced the idea that rational thinkers are sensitive to sameness of syntactic vehicle type precisely as an alternative to the claim that our conceptual capacities involved an unmediated sensitivity to the identity of our referents. Neither can they argue that this sensitivity to sameness of guise is based on sensitivity to some feature that is at best contingently connected to sameness of reference. If guises are to figure as Senses and, thereby, enable the Fregean to explain our rationality in forming an inference in terms of our appreciation of its validity, then our sensitivity to the sameness of guises cannot consists of sensitivity to features that fall short of ensuring validity.

To see this, consider a linguistic example analogous to our case of thought: I cannot be sensitive to the validity of my inference by noticing that two premises uses same-sounding words, for the premises might employ homonyms with different referents. Validity requires necessary truth preservation, and sameness of word-sound can at best contingently ensure truth-preservation. Hence, if I am to be sensitive to validity, rather than simply validity conducive features, then I must latch onto some syntactic features whose sameness by necessity ensures sameness of reference. The difficulty is in finding some syntactic feature that we can reasonably be said to be sensitive to the sameness of, which falls short of outright being the sameness of reference, yet which is sufficient to ensure necessary sameness of reference.

A series of prominent Fregean Guise accounts simply leave it as a primitive fact that the co-referring concepts in certain thoughts are formally logically related by the subject (Fine 2007; Heck 2012; and Pryor 2016). To share a guise is simply for two co-referring thoughts to be formally related in the subject's cognition. While this account might initially seem satisfactory as an explanation of our sensitivity to validity, it becomes inadequate once we realize that for certain inferences, notably those raised by the current puzzle, it seems like the reference fixing features of our Senses pull in opposing directions. This is a puzzle that needs answering, and to do so one needs to provide a positive account of the nature of the syntactic guises, and of how formally relating such co-referring concepts can make 
Prepublication version - please cite the published version.

it rational for a subject to both treat two premises as trivially co-referring and individually immune with respect to different pieces of information.

There are two prominent examples of Fregean Guise theories that provide substantial positive accounts both of what guises are and how we grasp their sameness. I will consider them in turn, starting with the approach developed by Tyler Burge (1998). He suggests that our syntactic grasp of sameness of representational vehicle consists in a sensitivity as to when concepts are reused. Guises are simply reference bearing syntactical units with a given reference that is settled by relations to one's social and physical environment. Reuses of the same singular concept consists in reuse of the same guise, and thus by necessity share reference. If two uses of a concept didn't share reference, there wouldn't be a reuse of the same concept. Hence, reuse is a syntactic feature that, not only isn't simply sameness of referent itself, but still ensures co-reference. Thus, our grasp of reuse of syntactical vehicles mediates our sensitivity to sameness of reference.

This explanation might indeed account for parts of our capacity for rational inference, such as our sensitivity to the validity of inferences based on anaphora. However, the explanation in terms of sensitivity to reuse won't work for the puzzling inferences with which we are concerned. Todd's first use of the demonstrative 'that lion' has its reference tied to his information about the jumping incident. Moreover, Tod must be sensitive to the fact that his demonstrative has its reference tied to this jumping-information. It is due to this sensitivity that Todd can appreciate his initial premise as possessing immunity. The Fregean Guise theorist then suggests that Todd's appreciation of the validity of his Hesperus-Hesperus inference comes down to his appreciation of the fact that the same demonstrative concept is reused in his second premise ${ }^{35}$. Yet, how can Todd possibly remain rational in treating his second use as a mere reuse of the concept from the first premise, all the while he also takes his second premise to possess immunity with regards to some entirely different piece of information?

If grasp of sameness of Sense is simply a syntactic grasp of reuse, then such grasp of sameness of Sense can never explain how we can be rational in treating two concepts that share sense as having immunity with regard to separate information. Per the Fregean Guise theorists own claim, Todd has no direct sensitivity to the sameness of the referent of his thoughts. So how can he possibly remain rational

35 This is a case of what has sometimes been called 'de jure co-reference' in the literature. See for example Recanati (2012, 92-93). 
Prepublication version - please cite the published version.

while he, on the one hand, on syntactic grounds alone treats a subsequent use of the demonstrative schema 'that lion' as a reuse of a former demonstrative and, on the other, treats the subsequent use as having its reference tied to different information than that governing his initial use? We cannot trivially treat a concept as a reuse of an earlier used concept, all the while, we also treat it as trivial that it refers to the object, we currently receive information about ${ }^{36}$. The account of grasp of Sense as a mere syntactic appreciation of reuse cannot explain the complex, yet rational, cognitive role that the two demonstrative concepts possess in Todd's case.

The second substantial Fregean Guise approach has been most extensively developed by Recanati $(2012)^{37}$. He argues that we should conceive of singular representational vehicles as a form of mental files, where each such file is individuated in term of its cognitive function as a storage for information received from a specific epistemically rewarding relation (ER-relation) to a single particular (Ibid, 20). Acquaintance, or, less technically, perception of an object, is a prime example of such an epistemically rewarding relation. Importantly, the actual reference of such a mental file is the "the dominant source of information in the file" (ibid, 140). This means that every reuse of such a representational vehicle will co-refer; with reference failure occurring when there is no dominant source of the information in the file ${ }^{38}$. This allows that while a mental file functions to refer to a single particular, it may in fact contain information that derives from several different ones; and in that way fall short of perfectly satisfying its function.

The way all of this relates to Sense and inferences that trivially rely on co-reference is that, according to Recanati, "mental files...have a function or a role which determines their cognitive significance" (2012, 245). Importantly, grasp of this cognitive significance, that is, grasp of Sense, doesn't consist in the different functions of the mental files being represented by the subject. Rather, different Senses are grasped by the subject through the practically different roles that the syntactic labels of these mental

\footnotetext{
${ }^{36}$ It is precisely this issue which has led many to reject Burge's anaphoric account of co-reference in those slow-switching cases where the second premise of one's reasoning is an immediate demonstrative perceptual judgement. See Recanati (2012, 120 -132) and Brown (2004, 176-182) for an overview of the debate.

${ }^{37}$ Despite terminological differences, Fodor's (2008) view is in all relevant respects similar. Recanati (2012:245) acknowledges this.

${ }^{38}$ Recanati $(2012,139-140)$ does acknowledge distinguishable regions of the information in the file may uniquely govern reference in separate cases; thereby allowing for differences in reference between separate uses of the same representational vehicle. However, he denies that this can occur when the representational vehicles are combined in inference, so we can ignore this issue for present purpose.
} 
Prepublication version - please cite the published version.

files actually play in the cognitive life of the individual (ibid, 248). Hence, it is because my subconscious cognition treats a set of information as being unified in single file with the function of storing information from one particular, that all my judgements which exploit that particular file or its label counts as sharing a Sense. By using the label or address for that file, I can then employ that singular concept even in thoughts that do not involve predication based on information that is stored in this way (ibid, 37). Unlike on Burge's theory, for Recanati grasping a shared Sense it isn't simply a matter of de jure stipulating that two information-involving judgement co-refer. Rather, it is a matter of the subject's sensitivity to the fact that certain information involved is already cognitively stored in a single file.

Recanati's view is exceptionally close to the object-dependent view of Sense. Both views argue that sharing a Sense is a matter of syntactically treating a set of information as deriving from a single object. The difference is a matter of which capacities we employ in unifying the information in question. According to the object-dependent view of Sense, it is through having a consciously accessible direct epistemic relation to the referent itself that we classify the information as pertaining to the same object. On Recanati's view, no such direct epistemic relation to the referent is involved. Rather, the existence of such a direct epistemic relation forms the normative ideal that governs our unification of information, but its existence or lack thereof plays no functional role in how we appreciate a set of information as co-referring (ibid, 63). On Recanati's view shared Sense is simply a matter whether two concept tokens draw information from the same file (or in the case of thoughts that aren't information-based a matter of employing the same label for the same file). We grasp shared Sense in conscious inference through our appreciation of how we have actually subconsciously bundled information (Ibid, 37). On Recanati's theory it is the mere cognitive bundling of information that individuates a mental file, with actual shared ancestry from a single object forming a normative ideal that determines the Sense or cognitive role of that file. In contrast on the object-Dependent view of Sense, it is the actual use of an epistemic relation to an object in bundling information that both individuates the syntactic mental vehicle and determines its Sense.

The problem with Recanati's account of Sense is that it makes it impossible to see how Todd's two demonstrative judgements can employ a single mental file, all the while both judgements remain individually immune. According to Recanati, a mental file refers to the object from which the dominant 
Prepublication version - please cite the published version.

part of the information in the file derives. This way of fixing reference follows from Recanati's claim that shared ancestry forms a mere ideal, rather than an actual requirement on the information used in judgements with shared Sense. In Todd's case the individuation of his mental files doesn't in any way ensure that the dominant source of the information in the file is, for example, the object from which he has falling information. Of course, that is the case in Todd's situation, but the syntactic feature that Todd is sensitive to doesn't ensure this. This means that even while Tod perfectly grasps the Sense, that is the cognitively role of his judgements, it may still be the case that a mental file of his somehow contains mixed information. Given the conceptual capacities in Todd's possession, there is nothing which makes its unreasonable for Tod to wonder as follows: I know something is falling, but is it that lion which is falling? However, to call a judgement immune is precisely to claim that, given the conceptual capacities involved by the subject, such doubt is necessarily unreasonable. This form of doubt isn't simply unreasonable in the sense that one would be epistemically blameless in going on without considering that issue, such as is the case with those defeaters which one need not rule out to possess knowledge. Rather, immunity to error of misidentification is meant to entail that it is unreasonable to even imagine that the referent of one's thought might not be the object from which one's information derives. But that case is surely imaginable given Recanati's account of Sense in terms of mental files; in fact, it is even possible that this is the case whenever multiple pieces of information are contained in the same file.

If Todd's judgements are each to be immune, then the nature of the syntactic vehicle that Todd is sensitive to must ensure that respectively the jumping and the falling information derives from the dominant source of information in the mental file employed in his demonstrative judgements. But when our grasp of Sense simply amounts to an appreciation of actual information storage, combined with grasp of the mere normative ideal of shared ancestry for that information, then grasp of Sense will only explain how Todd can rationally accept immunity if Todd opened different mental files in the case of each demonstrative judgement. But if that was the case, then it seems that Todd's two token uses of 'that lion' play different functional roles. The first 'that lion' would label the mental file that functions to refer to the object which his jumping information derives from, since that information dominates that file. The second 'that lion' would label the mental file has the function of referring to the object from which his falling information derives, since this information dominates the latter file. But given 
Prepublication version - please cite the published version.

Recanati's own view, representational vehicles with different functional roles have difference Senses; hence, Todd would in this case be irrational in using his concepts in a Hesperus-Hesperus type inference, since that requires sameness of Sense.

Recanati claims that we grasp Sense, not in terms of any epistemically relevant relations to referents, but simply through an appreciation of how information is cognitively stored combined with a grasp of the mere ideals for that storage. But if this is the case, then we cannot explain how we can both treat it as trivial that a bundle of information co-refers while also treating it as impossible that one piece of the information derives from an object different from the referent of that bundle. Recanati's only way out of the predicament would be to treat it as definitional of the mental file in question that it referred to the object from which both pieces of information derived. But in that case, we would back to the problem that faced the descriptivist, where our inference can at best provide Todd with knowledge that his demonstrative concepts refer at all, and that isn't the knowledge he is lacking in our case.

We have thus far seen that the traditional Fregeans seem unable to provide an account of what Senses are and how we grasp them, such that it can be our grasp of Sense which explains the complex cognitive role played by Todd's demonstrative concept 'that lion'. The moment we explain our grasp of Sense as a form of sensitivity to an intermediary that in turn settles reference, then it is, given the theories thus far considered, impossible to explain how that type of intermediary can both ensure the co-reference of Todd's two uses of his concept, and ensure that Todd's concepts are individually immune, all the while his inference provides him with the novel knowledge considered. Of course, novel Fregean Guises theories may be developed that can be shown to succeed, but thus far the prospects look grim. With that in mind, it is time to turn to the Object-dependent Fregean view of Sense in order to show how it solves the Fregean puzzle at hand.

\section{The solution in terms of object-dependent Senses}

The core challenge for the traditional Fregeans is that they want the order of explanation to run from grasp of sameness of Sense to grasp of the sameness of the referent. For them, it is precisely our grasp of the intermediary Senses that allows us to explain how we can grasp sameness of reference, despite our lack of direct epistemic access to the referent. This order of explanation is reversed on the ObjectDependent account of Fregean Senses. On such views, grasping a Sense amounts to standing in a consciously accessible direct epistemic relation to a referent which immediately allows you to grasp the 
Prepublication version - please cite the published version.

shared reference among a series of uses of singular concepts ${ }^{39}$. This means Senses are objectdependent, as I cannot stand in an epistemic relation to $\alpha$ if $\alpha$ doesn't exist.

This object-dependent view of Senses has been particularly favoured as an account of our grasp of the Sense of demonstratives ${ }^{40}$. This is precisely because it allows us to explain how we grasp that two uses of a demonstrative schema, say 'that lion', are uses of the same concept by explaining this in terms of both uses being based on one and the same epistemic relation to their referent. The order of explanation is thus reversed compared to the traditional Fregean. We start from our characterization of a subject as possessing a sensitivity to the identity of a particular. It is then in terms of this sensitivity that we explain how he can appreciate his concepts as sharing Sense. What it is for two singular concepts to share a Sense is for a subject's rational use of them both to be based upon the same epistemic relation between the thinker and an object ${ }^{41}$. Such epistemic relations are partly individuated in terms of the identity of the object related to, which then trivially ensures that two concepts that have their reference based on the same relation will share referents. For two concepts to share a Sense simply is for the subject to immediately and adequately appreciate their shared reference based on an epistemic relation to the referent. Hence, on the Object-Dependent view, we cannot use appreciation of sameness of Sense as a substantial explanation of our appreciation of sameness of reference.

The immediate challenge for the defender of object-dependent Senses is to explain how we can possess such direct awareness of sameness of reference, when it is an undeniable empirical fact that we at times overlook or mistake identities in our reasoning. While I won't have space to deal with this in depth here, the short explanation is the following: Cases where we fail to notice that two concepts co-refer are explained in terms of there being multiple different epistemic relations to the same object, each of which account for a separate Sense. In other words, my direct sensitivity to the sameness of referents among used concepts is conditional on these concepts being based upon a single epistemic relation to the referent. When they are so based, they share a Sense. Conversely, cases where I mistakenly take concepts to trivially co-refer are explained in terms of the intransparency of differences of Sense. While

\footnotetext{
${ }^{39}$ See Campbell (2002) and McDowell (1977 \& 1984)

40 See Brewer (2011), Campbell (2002), Evans (1982).

${ }^{41}$ McDowell (1977) rejects that any further account of Sense can be given. Brewer (2011), Campbell (2002), and Evans (1982) all try to provide substantial elaborations of the nature of Sense in terms of various epistemic relations between subject and object which they claim underlie our rational concept use.
} 
Prepublication version - please cite the published version.

I will always have rational access to the fact that two concepts share a Sense, it may at times be inaccessible to me that two concepts do not share a Sense ${ }^{42}$.

With the picture of object-dependent Senses in play, it is quite simple to explain Todd's case. When viewing the lion cub, Todd stands in an epistemic relation to it which grants him direct awareness that his separate uses of 'that lion' share reference. Every use of a concept which has its basis in that continuing epistemic relation between Todd and the lion cub will transparently to Todd refer to one and the same object. This capacity is what allows Todd to appreciate that his two premises co-refer, and thus, allows him to appreciate the validity of his inference. Hence, we can explain Todd's rationality in terms of his appreciation of the validity of his inference. Todd's epistemic relation to the lion cub also grants him the fallible ability to discern some of its features. On one occasion he discerns that it is jumping. As it is the very same epistemic relation which both provides him with fallible information about jumping and which grants him knowledge of the referent of his demonstrative, Todd can remain certain that if there is indeed something which jumped then it is the referent of his demonstrative. On a separate occasion, he uses the same epistemic relation in the same way to acquire knowledge about the falling incident.

We thus have three capacities in play. Todd's capacity to appreciate jumping-information as coming from the epistemic relation governing his first use of the demonstrative 'that lion'. His capacity to appreciate his falling-information as coming from the epistemic relation governing his second use of the demonstrative 'that lion'. And his capacity to appreciate both uses of 'that lion' as having the same referent due to both demonstratives being based upon the same epistemic relation to a single particular. When Todd rationally forms his Hesperus-Hesperus inference he exploits how these three capacities interrelate to acquire novel empirical knowledge. This picture allows us to explain how Todd can rationally retain the immunity of both his initial premises, appreciate the validity of his immediate Hesperus-Hesperus inference, and gain novel knowledge upon performing that inference. The crucial move that allows the Object-Dependent Fregean to dissolve the Puzzle is that, unlike the traditional Fregean, he doesn't view Senses as an intermediary which is meant to explain our ability to grasp sameness of reference. Rather, attributing sameness of Sense to two concepts is simply another way of

\footnotetext{
${ }^{42}$ See Campbell (1987), and Gersel (2016) for a discussion of why transparency of sameness of Sense is defendable while denying the transparency of differences of Sense. See Brown (2004) for disagreement.
} 
Prepublication version - please cite the published version.

saying that the subject stands in an epistemic relation to the referent that allows immediate grasp of the sameness of reference of two concepts. Explicating the nature of Sense then becomes a matter of explicating the many forms of substantial epistemic relations between subjects and objects which can support our immediate knowledge of the co-reference of our concepts.

\section{The Non-Fregean Alternative}

Thus far, I have argued that if we want to account for the rationality of the puzzling inferences in terms of our sensitivity to their logical validity, then we must accept that our conceptual capacities for singular thought consist partly of an unmediated epistemic relation to the referents of those thoughts. Hence, the Puzzle shows that if one is to remain Fregean, then one ought to acknowledge that singular demonstrative thoughts possess object-dependent Senses. But another alternative is to simply give up the Fregean ambition of explaining the rationality of an inference in terms of the thinker's sensitivity to the logical validity of the inference. Instead, Non-Fregeans argue that rational inference consists in sensitivity to the presence of features that can be shared among thoughts with different referents, thereby, allowing propositional states with different truth-conditions to play identical rational roles ${ }^{43}$. Of course, the Non-Fregean views need to hold onto the idea that the laws of proper inference are truthrelated. Otherwise, they would have sacrificed the platitude that judgement aims at truth. However, they will argue that rational inference only requires that we are sensitive to the presence of features which are conducive to the validity of the inference or reliable signs that the inference is valid under ordinary conditions. Such views generally argue that sensitivity to validity itself is a rationalist pipedream, which can never be satisfied by thinkers such as us due to the ever-present possibility of misleading empirical conditions.

It is, however, important to notice that the debate between Non-Fregean and Fregean views doesn't turn on the issue of infallibility or the unconditionality of a subject's capacity for valid inference. The Object-Dependent Senses view must acknowledge that various empirical conditions must be satisfied before we are sensitive to the validity of our Hesperus-Hesperus inferences. When subtle cases of switching make us mistake two objects for one and, thereby, make us engage in faulty Hesperus-

\footnotetext{
${ }^{43}$ This is view is endorsed by Brown (2004), Millikan (1993). Notice it is possible to hold this view regarding linguistic reasoning while denying it for mental inference, See Burge (1979). If Harman (1986) had endorsed his idea that there were rational yet non-logical immediate implications, then his view would figure as non-Fregean.
} 
Prepublication version - please cite the published version.

Hesperus type inferences, it is a sign that we cannot always discern when we stand in different epistemic relations to objects. When hostile conditions obtain, even the most conscientious thinker will be prone to engage in invalid inferences; and will thus be considered irrational by the Fregean. The point of contention isn't whether our ability to discern valid inferences is conditional, the question is whether the subject's who engage in invalid inferences should always be considered irrational, though possibly blameless, or whether such thinkers are sometimes every bit as rational as someone who properly engages in valid inference.

The non-Fregean defends the latter position. On their view, we are, even in the best of cases, responding to the presence of features that are shared between the subtle switching case and the ordinary one-object case ${ }^{44}$. In performing a Hesperus-Hesperus inference, we may, for example, be responding to our experience of the looks of things. Such looks are claimed to be shared between the case where I continuously see one lion cub and the case where two visually indistinguishable lion cubs are dexterously exchanged with each other. To be rational in one's Hesperus-Hesperus inference is to perform the inference based one one's sensitivity to the presence of these common features. Importantly, such sensitivity cannot amount to a sensitivity to validity, for those features are present even in cases when the inference is invalid. Rather, to be rational is to infer based on one's sensitivity to features that are reliable signs of validity. Hence, to the non-Fregean, our reasoner can be rational even when she performs an invalid Hesperus-Hesperus inference. This means that our capacity for rationality is unhindered by these adverse empirical conditions and can be exercised even in their presence. However, the deliverance of rational inference isn't a conclusion whose truth is ensured by the truth of the premises, but only a conclusion that is likely true given the premises' truth.

The difference is as follows: The Fregean claims that our capacity for rational inference is a capacity that we can conditionally exercise but whose exercise consists in an unconditional sensitivity to the validity of our inferences. The non-Fregean claims that our capacity for rational inference is a capacity that we can unconditionally exercise but whose exercise only grants conditional sensitivity to the validity of an inference. Hence, on both views, the rational subject's ability to infer validly is hostage to a fortunate environment. This means that the Non-Fregean can raise the following question: Given that

\footnotetext{
${ }^{44}$ See Brown (2004) for an extensive debate
} 
Prepublication version - please cite the published version.

both theories require the satisfaction of an external condition in their account of a rational subject's ability to validly infer, why should we place the externalism where the Fregean does?

Providing a full response to this question is a task that would take the present paper beyond all reasonable length. However, I do want to raise a challenge that uniquely faces the non-Fregean approach. At first, it is important to notice that the debate need not take the issue of epistemic externalism or reliabilism as its central turning point. I have already acknowledged that the Fregean must acknowledge some form of externalism ${ }^{45}$. Likewise, the Fregean would do well to acknowledge that we can at times acquire knowledge by relying on reliable rather than truth-ensuring procedures. What I take to be the central challenge for the non-Fregeans is to provide an account of why we should take a thinker, that is solely in possession of the conceptual capacities they award us, to issue thoughts that are aimed at realist truth. In other words, why should we take such thinkers to respond to the truthconducive features because they fallible signs of truth, where realist truth figures as the aim of the judgement. The alternative is to take them to be treating the presence of these features themselves as the full requirement for proper thought. Notice that on the Non-Fregean view, any subsequent rational correction that a thinker may make to his initial judgements will likewise be a response to features that falls short of ensuring the truth of his new judgement. So, our potential for self-correction will bring us no closer to an explanation.

On the Fregean view, we can explain the aim of thought in terms of the features that effectively guide a rational thinker's behavior, which is the ensured truth of his conclusion. His faulty inferences can then be seen as failures to attain this aim caused by external conditions inhospitable to the exercise of his capacity for rational inference. No analogous two-stage explanation is available to the non-Fregean. For on the non-Fregean view, we can always, even under the most unfortunate empirical conditions, fully exercise our capacity for rationality and, therefore, this capacity cannot provide sensitivity to validity. Rational thinkers are solely, albeit unconditionally, sensitive to something that falls short of ensuring the truth of their conclusions.

Compare an ordinary account of the use of following signposts as a means in attaining a distinct goal, say, that of reaching a specific place. Somewhere in a normal account, the subject that uses the

45 The only way of avoiding this is by endorsing internalism of content, which is by now a minority view. Dummett (1975: 131) and Boghossian (2011) take this approach. 
Prepublication version - please cite the published version.

signposts as a means to a different end must possess the disposition to let the direction suggested by the signpost be trumped by direct information about the goal itself. If the last signpost was turned wrongly, and our target continued unperturbed past the clearly recognizable destination, then we would have grounds for denying that he used the signpost as means to reach that destination. Rather, he would be taking the following of the sign post to the be the very success condition for his action. The Fregean can present a similar story where under fortunate conditions we are directly rationally guided by sensitivity to the very aim of thought, namely, the truth of our conclusion. In the case of inference, this is exemplified through sensitivity to validity. The non-Fregean will have to acknowledge that we are never under any conditions guided by truth itself. But what then are the empirical conditions which define us as thinkers aimed at realist truth. Truth has become a completely idle element in the nonFregean's account of the psychology of rational subjects.

This final discussion clearly doesn't do justice to the debate between Fregean and Non-Fregeans. Yet, it does raise a question that besets only the non-Fregean which they have to answer in order to figure as a viable alternative to Fregean theories. What I have argued in this paper is that if one is committed to a Fregean approach to the theory of meaning, then one should accept that some of our singular thoughts, demonstrative thoughts in particular, are individuated in terms of Object-Dependent Fregean Senses. Because, only if they are, can we account for the rationality of the Hesperus-Hesperus inferences we employ in unifying our separately acquired pieces of empirical information into a single comprehensive picture of the temporally extended lives of physical particulars. Alternative Fregean theories are unable to explain how we can rationally take Hesperus-Hesperus inferences to be trivially valid, all the while we continue to treat the employed premises as immune to errors of misidentification with regard to separately acquired information; and neither assumption can be given up if we want a non-skeptical account of our empirical knowledge gathering capacities. 


\section{Bibliography}

- Bach, K (2010) "Getting a Thing into Thought" in Robin Jeshion (ed.), New Essays on Singular Thought. Oxford University Press

- Boghossian, P. (1992) "Externalism and Inference" in Philosophical Issues 2: 11-28

- Boghossian, P. (1994) "The transparency of Mental Content" in Philosophical Perspectives 8: 33-50

- Boghossian, P. (2011) "the Transparency of Mental Content Revisited" in Philosophical Studies 155: $457-465$

- Boghossian, P. (2014) “What is Inference?” in Philosophical Studies 169: 1-18

- Braun, D. (2001) "Russellianism and explanation", in Philosophical Perspectives 15: 253-89.

- Brewer, B. (2011) Perception and its Objects. Oxford University Press, Oxford.

- Broome, J. (2013) Rationality through Reasoning. Oxford: Wiley-Blackwell.

- Brown, J. (2004) Anti-individualism and Knowledge. MIT press, Cambridge Mass.

- Burge, T. (1977) "Belief De Re" in Journal of Philosophy 74: 338-362.

- Burge, T. (1979) "Sinning against Frege" in Truth, Thought and Reason. Oxford University Press: Oxford: 213-239.

- Burge, T, (1979). "Individualism and the Mental," in Midwest Studies in Philosophy, IV, Minneapolis: University of Minnesota Press: 73-121.

- Burge, T. (1993) "Content Preservation" in Philosophical Review 102: 457-488

- Burge, T. (1998) "Memory and Self-Knowledge” In Peter Ludlow \& N. Martin (eds.), Externalism and Self-Knowledge. Centre for the Study of Language and Information

- Burge, T (2009) "Five theses on De Re states and attitudes" in The Philosophy of David Kaplan, Almog, J. (ed.) Oxford University Press, Oxford.

- Campbell, J. (1987) "Is Sense Transparent?" in Proceedings of the Aristotelian Society 88: 273292

- Campbell, J. (2002) Reference and Consciousness. Oxford University Press, Oxford.

- Caroll, L. (1985) "What the Tortoise said to Achilles" in Mind 4: 278-80

- Chalmers, D. (2002) "The Components of Content" in Philosophy of Mind: Classical and Contemporary Readings. Oxford University Press, Oxford. 
- Dickie, I. (2015) Fixing Reference. Oxford University Press, Oxford.

- Dummett, M. (1973) Frege: Philosophy of Language. Duckworth, London

- Dummett, M. (1975) "Frege's Distinction between Sense and Reference" in Truth and other Enigmas. Harvard University Press, Cambridge Mass.

- Evans, G. (1982) The Varieties of Reference. Oxford University Press, Oxford

- Fine, K. (2007) Semantic Relationism. Blackwell Publishing, Oxford

- Frege, G. (1879) "Begriffsschrift, a formula language, modeled upon that of arithmetic, for pure Thought", trans. Stefan Bauer-Mengelberg, in Jean van Heijenoort ed. From Frege to Gödel: A Source Book in Mathematical Logic, 1879-1931. Harvard University Press, Cambridge Mass: $1-82$.

- Frege, G. (1892) “On Sense and Reference”, In Philosophical Writings, eds. P. Geach and M. Black. Blackwell, Oxford.

- Frege, G. (1906) "17 Key Sentences on Logic" (1906 or earlier) - in: Frege: Posthumous Writings - Edited by Hans Hermes, Friedrich Kambartel, Friedrich Kaulbach - Chicago, The University of Chicago Press: 174-175

- Frege, G. (1918) “The Thought” in Mind 65 (259): 289-311

- Fodor, J. (1990) "Substitution Arguments and the Individuation of Beliefs," in his A Theory of Content, and Other Essays. MIT Press: Cambridge, Mass: 161-76

- Fodor, J. (1994) The Elm and the Expert. MIT Press, Cambridge Mass.

- Fodor, J. (2008) LOT 2: The language of Thought Revisited. Oxford: Clarendon Press.

- Forbes, G. "Review” (of Nathan Salmon's Frege's Puzzle) in Philosophical Review 96: 455-8

- Gersel, J. (2017) “What Motivates Fregean Anti-Individualism?” in Grazer Philosophische Studien 94: 153-172

- Harman, G. (1986) A Change in View. MIT Press, Cambridge Mass.

- Heck, R. (1995) "The sense of communication", in Mind 104: 79-106

- Heck, R. and May, R. (2010) "The composition of thoughts" in Noûs 45: 126-66.

- Heck, R. (2012) “Solving Frege's Puzzle” in Journal of Philosophy 109: 132-174

- Heck, R. (2014) “In Defence of Formal Relationism” in Thought 3: 243-250

- Jession, R (ed.) (2010) New Essays on Singular Thought, Oxford University Press, Oxford 
Prepublication version - please cite the published version.

- Kripke, S. (1980) Naming and Necessity. Cambridge, MA: Harvard University Press.

- Littlejohn, C. (2013) “The Russellian Retreat”. Proceedings of the Aristotelian Society 113: 293-320

- Martin. M. (2002) "Particular Thought and Singular Thought" in Royal Institute of Philosophy Supplement 51:173-214

- McDowell, J. (1977) "On the Sense and Reference of a Proper Name” in Mind 86:159-185

- McDowell, J. (1984) “De Re Senses” in Philosophical Quarterly 34: 283-294

- Millikan, R. (1993) White Queen Psychology and other Essays for Alice. MIT Press, Cambridge Mass.

- Millikan, R. (2000) On Clear and Confused Ideas: An essay about substance concepts. Cambridge University Press, Cambridge

- Perry, J. (1977) "Frege on Demonstratives" in Philosophical Review 86: 474-497

- Pryor, J. (2001) "Highlights of Recent Epistemology" in The British Journal for the Philosophy of Science 52: 95-124

- Pryor, J. (2016) "Mental Graphs" in Review of Philosophy and Psychology 7: 309-341

- Recanati, F. (2012) Mental Files. Oxford University Press, Oxford

- Searle, J (1982) "Proper Names and intentionality" in Pacific Philosophical Quarterly 63: 205225

- Sainsbury, R and Tye, M. (2012) Seven Puzzles of Though and How to Solve Them: An Originalist Theory of Thought. Oxford University Press, Oxford.

- Salmon, N. (1986) Frege's Puzzle. MIT Press, Cambridge Mass.

- Shoemaker, S. (1968) "Self-Reference and Self-Awareness" in Journal of Philosophy 65: 555567

- Smithies, D. (2012) “The Normative Role of Knowledge”. Noûs 46: 265-288.

- Textor, M. (2011) Frege: On Sense and Reference. Routledge: London

- Travis, C. (2007) 'Reasons Reach' in Perception - Essays after Frege. Oxford: Oxford University Press. 2013

- Wright, C. (2004) "Warrant for nothing (and foundations for Free?)" in Aristotelian Society Supplementary Volume 78:167-212 